\title{
Sosyo
}

Ekonomi

July-December

2014-2

\section{Milli Eğitim Bakanlığı Bütçe Tahminlerinin Doğruluk İlkesi Açısından Değerlendirilmesi}

Sibel ÖZCAN

Mustafa Umur TOSUN

sibel.ozcan@hacettepe.edu.tr

utosun@ hacettepe.edu.tr

\section{An Evaluation of Budget Estimates of Ministry of National Education from the Point of Accuracy Principle}

\begin{abstract}
Education expenditure has a significant role in the strengthening of the economy. Therefore, this kind of expenditure has great importance for both politicians and bureaucrats as well as society in general. In this study, the accuracy of the expenditure budget estimates which made by MoE for the period 1924-2012 was examined. For the assessment of accuracy we calculate forecast error, Theil's inequality coefficient and test the forecast's rationality. As a result we see that the estimations of initial allowances are under forecasted while the final allowances are over forecasted and final allowance estimates are more accurate than initial allowances.
\end{abstract}

Keywords

: Forecast Error, Theil's Inequality Coefficient, Rational Expectation.

JEL Classification Codes : $\quad$ E62, H68, H52.

\section{Özet}

Eğitim harcamaları ekonominin güçlenmesinde önemli bir role sahiptir. $\mathrm{Bu}$ nedenle bu alana yapılan harcamalar hem politikacılar ve bürokratlar hem de toplumun geneli açısından büyük öneme sahiptir. Çalışmada 1924-2012 döneminde MEB tarafından yapılan gider bütçesi tahminlerinin ne derece doğru olduğu incelenmiştir. Tahminlerin doğruluğunun incelenmesi tahmin hatası, Theil'in eşitsizlik katsayılarının hesaplanması ve tahminlerin rasyonel beklentilere uygunluğunun test edilmesi üzerinden yapılmıştır. Sonuç olarak dönemin genelinde başlangıç tahminlerinin düşük, yılsonu ödenek tahminlerinin yüksek yapıldığı; yılsonu ödenek tahminleri başlangıç tahminlerine kıyasla daha başarılı olduğu görülmüştür.

Anahtar Sözcükler $\quad$ : Tahmin Hatası, Theil'in Eşitsizlik Katsayıları, Rasyonel Beklentiler. 
Sibel ÖZCAN \& Mustafa Umur TOSUN 


\section{Giriş}

Eğitimin finansmanı, özellikle kamusal eğitimin finansmanı, gerek politikacıları ve kurum yöneticilerini gerekse de toplumu yakından ilgilendiren önemli bir başlık olarak iktisat yazınındaki yerini almaktadır. Eğitim, uzun zamandır ekonomik hareketliliğin ${ }^{1}$ (mobilite) kaynağı olarak görülmektedir (Berger ve Fisher, 2013: 3). Berger ve Fisher (2013)'in bulgularına göre; iyi eğitimli işgücü ile yüksek ücretler arasında açık ve güçlü bir korelasyon bulunmaktadır. Ayrıca, eğitime yatırım yapmak emek piyasasında ilerleyen dönemlerde ücret artışlarıyla birleşen yüksek vergi hasılatı anlamına geldiğinden vergi gelirleri üzerinde de olumlu bir etki ortaya çıkarmaktadır. Bu noktadan hareketle devlet, eğitime yatırım yaparak güçlü bir ekonominin temellerini atmış olabilmektedir. Eğitime yapılan yatırımların büyüklügü kadar, tahsis edilen bütçe ödeneklerinin tahmini, tahmin ile gerçekleşme arasındaki farkın büyüklügü de önemli bir unsur olarak karşımıza çıkmaktadır. Zira yılsonunda kullanılmayan ödenekler yılsonu tenkis işlemleri ile iptal edilmekte ve plânlananın aksine eğitim için harcanamayan bir miktar olarak karşımıza çıkabilmektedir.

Çalışmada, 1924-2012 yılları arasında genel bütçeden ortalama olarak yaklaşık \%10'luk bir paya sahip olan Milli Eğitim Bakanlığı'nın bütçe tahminleri incelenmektedir. Cumhuriyetin ilk bütçesi olan 1924 yılı bütçesinde Milli Eğitim Bakanlığı'nın (Maarif Vekâleti) \%4,4'lük bir paya sahip olduğu görülmektedir. Zaman içerisinde Milli Eğitim Bakanlığı'nın genel bütçeden almış olduğu pay artarak, 1992 yılında \%15,6 ile en yüksek seviyeye ulaşmaktadır. 2005 yılından itibaren ise Millî Eğitim Bakanlığı'nın genel bütçeden aldığı pay yaklaşık olarak \%10 olarak gerçekleşmiştir.

Topluma hizmet anlamında kamu kaynakları arasında var olan rekabet, kamu kaynaklarının etkin, etkili, verimli ve ekonomik olarak kullanımı yönündeki çabaların artmasına neden olmaktadır. Bu çalışma ile genel bütçeli idare olan Millî Eğitim Bakanlığı'nın bütçe tahminlerini ne derece doğru yaptığı tespit edilmeye çalışılııştır. Bu noktadan hareketle, çalışmanın birinci bölümünde konuya ilişkin yapılan çalışmalara yer verildikten sonra ikinci bölümde yöntemler açıklanmaktadır. Üçüncü bölümde elde edilen bulgulara yer verilmekte ve sonuç bölümüyle tamamlanmaktadır.

\section{Bütçe Uygulamalarında Doğruluk İlkesi ve Ampirik Literatür}

Bir maliye politikası aracı olarak bütçeler vasıtasıyla hedeflenen sonuçların elde edilebilmesi, bütçelerin gerçekçi olarak hazırlanmasına bağlıdır. Kamu idarelerinin bütçe tekliflerinin Temmuz ayı sonu itibariyle Maliye Bakanlığı'na göndermek zorunda olması göz önünde bulundurulduğunda bütçe tekliflerinin ilgili yıl öncesinde hazırlanmaya başladığı görülecektir. Bu da bütçelerin birer tahmin belgesi olduklarının altını çizmektedir.

I Ekonomik hareketlilik (mobilite), düşük gelirli bireylerin, ailelerin veya grupların genellikle gelir cinsinden ölçülen refahlarının iyileşmesi olarak tanımlanmaktadır. 
Zaten 5018 sayılı Kamu Mali Yönetimi ve Kontrol Kanunu'nda da bütçe “... Belirli bir dönemdeki gelir ve gider tahminleri ile bunların uygulanmasına ilişkin hususları gösteren ve usulüne uygun olarak yürürlüğe konulmuş..." belge olarak tanımlanmıştır.

Bütçe tahminlerinin uygulanacak olan politikaların başarısını doğrudan etkilemesi nedeniyle bütçe tahminleri objektif ve sübjektif açıdan ele alınmıştır. $\mathrm{Bu}$ değerlendirmeler ise sırasıyla bütçe ilkelerinden doğruluk ve samimiyet ilkelerine karşıllk gelmektedir (Gürsoy, 1980: 146).

Doğruluk ilkesi bütçe tahminlerinin içinde bulunulan şartlara uygun olarak hazırlanmasını gerektirir. Bu durumda ekonominin içinde bulunduğu durum objektif olarak analiz edilmeli ve bütçe tahminleri ile ne olduğundan iyi ne de olduğundan kötü bir tablo çizilmelidir (Edizdoğan ve Çetinkaya, 2010: 122-123). Samimiyet ilkesi ise bütçe tahminlerinin, tahmini yapanın gerçek düşüncelerini yansıtması, yapılan tahminlerin gerçekçi olduğuna samimi olarak inanmasını gerektirir (Gürsoy, 1980: 146). İlgili yılın sonunda gerçekleşmeler ile yapılan tahminler arasında ciddi farkların olması bu iki bütçe ilkesine uyulmadığı anlamına gelmektedir.

Konunun taşıdığı önem nedeniyle bütçe tahminlerinin doğruluğu farklı dönemler ve ülkeler için analiz edilmiştir. Yapılan çalışmalardan ilki Allan tarafından 1965 yılında İngiltere için yapılmıştır. Daha sonra ise farklı zaman aralıklarını kapsayacak şekilde İngiltere, Kanada, Hindistan, Pakistan, ABD ve Türkiye'de bütçe tahminlerinin doğruluğu ele alınmıştır.

İngiltere'de bütçe tahminlerinin doğruluğu iki ayrı çalışmayla ele alınmıştır. Bunlardan ilki, 1951-1963 dönemini ele alan yukarıda bahsedilen Allan (1965)'ın çalışması; diğeri ise 1951-1978 döneminin ele alındığı Davis (1979)'in çalışmasıdır. Allan tarafından yapılan çalışmada gelir ve gider bütçesi tahmin-gerçekleşme rakamları arasındaki fark değerlendirilmiş ve ilgili dönem içerisinde gelir tahminlerinin harcama tahminlerine kıyasla daha başarılı olduğu tespit edilmiştir (Allan, 1965: 323-325). Allan'ın çalışmasına kıyasla daha uzun bir dönemi ele alan Davis ise çalışmasında, ilave olarak Theil'ın eşitsizlik katsayılarını kullanmıştır. Davis, ele aldığı dönemi 1967 öncesi ve sonrası olmak üzere iki parçaya ayırmış ve sonuç olarak gelir tahminlerinde zaman içerisinde bir iyileşme, harcama tahminlerinde ise tam tersine bir kötüleşme olduğunu tespit etmiştir (Davis, 1980: 190-193).

Kanada'da ise benzer bir çalışma Theil'ın eşitsizlik katsayısı kullanılarak Auld (1970) tarafından 1949-1968 dönemi için yapılmıştır. Çalışmada zaman içerisinde gelir ve gider bütçesi tahminlerinin iyileştiği tespit edilmiştir. İlave olarak gider tahminlerinde yapılan hatanın düşük tahminden, gelir tahminlerinde ise yüksek tahminden kaynaklandığ tespit edilmiştir (Auld, 1970: 509-511).

Hindistan'da bütçe tahminlerinin başarısı ile ilgili olarak Asher (1978), Bhattacharya ve Kumari (1988) ve Chakraborty ve Sinha (2008)'ın çalışmaları mevcuttur. 
Asher'in yapmış olduğu çalışma tahmin ve gerçekleşme arasındaki farkın değerlendirilmesine dayanmaktadır. Çalışmada gelir ve gider bütçesinin her ikisinin de düşük tahmin edildiği; bununla birlikte gider bütçesinde gelire kıyasla daha fazla hata yapıldığı görülmüştür (Asher, 1978: 431). 1961-1986 dönemini ele alan Bhattacharya ve Kumari tarafından yapılan çalışmada ise Theil'in eşitsizlik katsayılarının yanı sıra bütçe tahminlerinin rasyonel beklentileri karşılayıp karşılamadığı test edilmiştir. Sonuç olarak da yapılan tahminlerin başlangıçta düşük, yıl içerisinde yapılan revizyonlarla ise yüksek tahmin edildiği; yapılan hataların gider bütçesinde gelir bütçesi tahminlerine kıyasla yüksek olduğu ve yapılan tahminlerin rasyonel beklentilere uygun olarak yapılmadığı görülmüştür (Bhattacharya ve Kumari, 1988: 13-27). Chakraborty ve Sinha (2008) tarafından ise 19902004 döneminde yapılan bütçe tahminleri ele alınmış ve Bhattacharya ve Kumari tarafından uygulanan yöntemler uygulanmıştır. Sonuç olarak gelir tahminlerinde gider bütçesi tahminine kıyasla daha fazla hata yapıldığg tespit edilmiştir. Bhattacharya ve Kumari’nin çalışmasında olduğu gibi rasyonel beklentilere uygun olarak bütçe tahminini yapılmadığı da elde edilen sonuçlar arasında yer almaktadır (Chakraborty ve Sinha, 2008: 15).

Zakaria ve Ali (2010) tarafindan, Pakistan devlet bütçesi için 1987-2008 döneminde, tahmin ve gerçekleşme arasındaki fark, Theil'in eşitsizlik katsayıları ve rasyonel beklentilere uygunluk testi yapılmıştır. Çalışmada revizyon sonrasında yapılan tahminlerde bir iyileşme olduğu, 2000'li yıllarda 1990’lı yıllara kıyasla daha fazla hata yapıldığı ve yapılan tahminlerin rasyonel beklentilere uygun olmadığı görülmüştür (Zakaria ve Ali, 2010: 125-127).

ABD'de yapılan bütçe tahminlerinin değerlendirilmesinde ise yine Theil'in eşitsizlik katsayısı kullanılmıştır. 1950-1983 yılları arasında federal bütçe tahminlerinde gider tahmininin gelire kıyasla daha başarılı olduğu görülmüştür (Morrison, 1986: 330).

Türkiye açısından ise Günlük Şenesen (2000) tarafindan yapılan 1983-1998 yılları arası, konsolide bütçe harcamalarındaki sapmaların yapısını araştırmaya yönelik olan çalışmada harcamaların tahminlerden daha yüksek olduğu tespit edilmiştir. Çalışmada harcama kalemleri ekonomik ve fonksiyonel sınıflandırmaya göre ayrı ayrı değerlendirilmiştir. Ayrıca çalışmada tahminlerdeki böyle bir sapmanın nedeninin enflasyon olup olmadığı incelenmiş ve sonuç olarak sapmalar üzerinde enflasyonun etkisinin olmadığı görülmüştür (Günlük Şenesen, 2000: 362-363). Konu ile ilgili olarak Bağdigen (2002, 2005)' in çalışmaları da mevcuttur. 1981-2000 döneminde vergi gelirleri tahminlerinin ele alındığı çalışmada yapılan tahminlerin başarılı olmadığ 1 ve yapılan hatanın düşük tahminden kaynaklandığı görülmüştür (Bağdigen, 2002: 36). Bağdigen (2005: 200)'in yaptığı diğer bir çalışmada ise 1981-2003 döneminde bütçe gelir ve harcama tahminleri analiz edilmiş ve gelirlerin yüksek, harcamaların ise düşük tahmin edildiği sonucuna varılmıştır. Son olarak Özcan (2012) 1924-2010 yılları arasında genel bütçe gelir ve giderlerini tahmin hatası, Theil'in eşitsizlik katsayılarını kullanarak ve yapılan tahminlerin rasyonel beklentilere uygunluğunu test ederek incelemiştir. Çalışmanın sonucunda gelir ve başlangıç 
ödeneklerinin düşük, yılsonu ödeneklerinin ise yüksek tahmin edildiği, yapılan tahminlerin rasyonel beklentilere uygun olmadığı sonucu elde edilmiştir (Özcan, 2012: 82).

Yukarıda sıralanan çalışmalarda ve bu çalışmada kullanılan yöntemler bir sonraki bölümde açıklanmıştır.

\section{Yöntem}

Çalışmalarda kullanılan yöntemlerden ilki tahmin hatasının hesaplanmasıdır. Tahminlerde yapılan hatanın gerçekleşmelerden ne kadar saptığını yüzde olarak ifade eden bu hesaplamada kullanılan formül aşağıdaki gibidir:

$$
\text { Tahmin hatası }=\frac{\text { Gerçekleşme }- \text { Tahmin }}{\text { Gerçekleşme }} \times 100
$$

$\mathrm{Bu}$ formülün yanı sıra yapılan çalışmalarda başka formüllerin² de kullanıldığı görülmüştür. Fakat bu çalışmada Rodgers ve Joyce (1996) ve Bağdigen $(2002,2005)$ tarafindan da kullanılan yukarıdaki formülden yararlanılacaktır.

Bakanlık harcamalarının tahmin edildiği gibi gerçekleşmesi durumunda hesaplanan tahmin hatası 0'a eşit olacaktır. Elde edilen hata büyüklüklerinin yorumlanması da bu mükemmel tahminin yapıldığı durumda elde edilebilecek olan 0 değerine kıyasla yapılır. Hesaplanan tahmin hatası 0 'dan uzaklaştıkça tahminlerin kötüleştiği söylenebilir.

Tahmin başarısını değerlendirmede kullanılan diğer yöntem ise Theil'in eşitsizlik katsayılarıdır. Theil (1965: 32) tarafından kullanılan ve $\mathrm{U}_{1}$ ile gösterilen ilk eşitsizlik katsayısı hesaplama formülü aşağıdaki gibidir:

$$
\mathrm{U}_{1}=\frac{\sqrt{\frac{1}{\mathrm{n}} \Sigma\left(\mathrm{P}_{\mathrm{t}}-\mathrm{A}_{\mathrm{t}}\right)^{2}}}{\sqrt{\frac{1}{\mathrm{n}} \Sigma \mathrm{P}_{\mathrm{t}}^{2}}+\sqrt{\frac{1}{\mathrm{n}} \Sigma \mathrm{A}_{\mathrm{t}}^{2}}}
$$

Formülde yer alan $\mathrm{P}_{t}$ tahminlerdeki değişimleri, $A_{t}$ gerçekleşmelerdeki değişimleri ve $\mathrm{n}$ ise gözlem sayısını ifade etmektedir.

2 Zakaria ve Ali (2010, s.116) tarafindan Tahmin hatası $=\frac{\text { Tahmin-Gerçekleşme }}{\text { Gerçekleşme }} \times 100$ formülü ile Günlük Şenesen (2000, s. 347) tarafindan ise Tahmin hatası $=\frac{\text { Gerçekleşme-Tahmin }}{\text { Tahmin }} \times 100$ formülü ile hesaplanmıștır. 
Bu ilk eşitsizlik katsayısı 0 ile 1 arasında değerler almaktadır. Katsayısının 0 değerini alması tahminlerdeki ve gerçekleşmelerdeki değişimlerin birbirine eşit olması halinde $\left(\mathrm{P}_{\mathrm{t}}=\mathrm{A}_{\mathrm{t}}\right)$ söz konusudur. 1 değerini alması ise tahmin ve gerçekleşmeler arasında ters orantılığın olması halinde mümkündür. Başka bir ifadeyle gerçekleşmeler pozitif iken tahminin negatif olması ya da tahmin pozitif iken gerçekleşmelerin negatif olması halinde en yüksek değer olan 1 elde edilebilecektir. En yüksek değerin elde edileceği bir diğer durum ise tahmin ya da gerçekleşmenin 0 değerine sahip olmasıdır (Theil, 1965: 33-34).

Theil (1971: 28) tarafindan ilk hesaplama formülünün paydasında değişiklik yapılarak elde edilen ikinci katsayı hesaplama formülü ise aşağıdaki gibidir:

$$
\mathrm{U}_{2}=\frac{\sqrt{\sum\left(\mathrm{P}_{\mathrm{t}}-\mathrm{A}_{\mathrm{t}}\right)^{2}}}{\sqrt{\sum \mathrm{A}_{\mathrm{t}}^{2}}}
$$

İlk formülde olduğu gibi bu formülde de $P_{t}$ ve $A_{t}$ değerleri tahmin ve gerçekleşmelerdeki değişimleri göstermektedir. Fakat farklı olarak bu formülde $U_{2}$ değerinin bir üst sınırı bulunmamaktadır. Theil tarafından birinci ve ikinci formül arasındaki bu farkın eşitliğin paydasındaki farklılıktan kaynaklandığı ifade edilmektedir (Theil, 1971: 28).

Yapılan çalışmalarda tahminlerin başarısı değerlendirilirken kullanılan bir diğer formül ise gerçekleşme farkının ve tahminle gerçekleşme arasındaki farkın kullanıldığı ve $\mathrm{U}_{3}$ olarak gösterilen formüldür ${ }^{3}$.

$$
\mathrm{U}_{3}=\frac{\sqrt{\frac{1}{\mathrm{n}} \Sigma\left(\mathrm{P}_{\mathrm{t}}-\mathrm{a}_{\mathrm{t}}\right)^{2}}}{\sqrt{\frac{1}{\mathrm{n}} \Sigma \mathrm{P}_{\mathrm{t}}^{2}}+\sqrt{\frac{1}{\mathrm{n}} \sum \mathrm{a}_{\mathrm{t}}^{2}}}
$$

$\mathrm{Bu}$ formülde diğerlerinden farklı olarak; $\mathrm{P}(\mathrm{t})=\mathrm{P}(\mathrm{t})-\mathrm{A}(\mathrm{t}-1)$ olarak, $\mathrm{a}(\mathrm{t})=\mathrm{A}(\mathrm{t})$ A(t-1) olarak hesaplanmıştır. Tanımlamalardaki bu farkın haricinde diğer 2 formülde olduğu gibi 0 sonucu mükemmel tahmini ifade eder.

Yapılan çalışmalarda bütçe tahminlerinin değerlendirilmesinde kullanılan bir diğer yöntem ise bütçe tahminlerinin rasyonel beklentilere uygun olarak hazırlanıp hazırlanmadığının test edilmesidir.

3 Bu formül Bhattacharya ve Kumari (1988, s. 1323,1324) Zakaria ve Ali (2010, s. 117) ile Chakraborty ve Sinha (2008, s. 6) tarafindan yapılan değerlendirmelerde kullanılmıştır. 
Hatırlanacağ 1 gibi rasyonel beklentiler hipotezine göre yapılan tahminlerin, tahmin edilen değişkenle ilgili bütün geçerli bilgiler dikkate alınarak yapılması gerekmektedir (Froyen, 2008: 229). Ayrica bilginin kısitlı olması nedeniyle ekonomik sisteminin bilgiyi harcamayacağı varsayılır. Yapılan tahminlerin sistemin genel yapısına bağlı olması nedeniyle bilgi miktarı ve sistemin yapısındaki değişikliklerin yapılan tahminleri de değiştireceği savunulur (Muth, 1961: 315). Rasyonel beklentilere uygun olarak tahmin yapılıp yapılmadığı aşağıdaki formül yardımıyla test edilir:

$$
A_{t}=\alpha_{0}+\alpha_{1} \mathrm{P}_{\mathrm{t}}+\alpha_{2} \mathrm{~A}_{\mathrm{t}-1}
$$

$\mathrm{Bu}$ denklemde $\mathrm{A}$ gerçekleşmeleri $\mathrm{P}$ ise tahminleri göstermektedir. Formülde aranılan katsayı değerleri ise $\alpha_{0}=0 ; \alpha_{1}=1 ; \alpha_{2}=0$ 'dır. İlave olarak tahmin hatası ile tahmin arasında bir ilişkinin olmaması $\sigma \mathrm{E}(\mathrm{t}) \mathrm{P}(\mathrm{t})=0$ gerekmektedir (Lovell, 1986: 113).

Açıklanan bu yöntemler kullanılarak bir sonraki bölümde 1924 yılından 2012 yılına kadar Milli Eğitim Bakanlığı ödenek taleplerinin ne derece doğru yapıldığı incelenmiştir. Bu noktada birkaç hususun altının çizilmesi gerekmektedir. Her şeyden önce bu çalışma ülkemiz açısından ekonomik büyümenin önemli kaynaklarından biri olan eğitim sektörüne yönelik olarak tek bir genel bütçeli idarenin, gider bütçe tahminlerinin doğruluk ilkesi açısından incelendiği ilk çalışma olma niteliği taşımaktadır. Yukarıda literatürde konuya ilişkin yapılan çalışmalar bölümünden de anlaşılabileceği gibi, tahmin ve gerçekleşmelerde yapılan hatalar hem gelir hem de gider yönünden yapılmıştır. $\mathrm{Bu}$ çalışmanın kapsamında incelenen Millî Eğitim Bakanlı̆̆g genel bütçeli bir idare olarak gelir tahmininde bulunmamakta ancak gider tahminlerinde bulunmaktadır. Genel bütçeli idareler açısından gelir tahmini Maliye Bakanlığı tarafından yapılmaktadır. Bu nedenle çalışmada sadece Bakanlığın gider tahminlerinin doğruluk ilkesi açısından sınanmasına yer verilmektedir.

\section{Bulgular}

Milli Eğitim Bakanlığı ödenek tahminleri incelenirken dönem bütçeleme sistemlerinde yapılan değişiklikler göz önünde bulundurularak üç döneme ayrılmıştır. $\mathrm{Bu}$ dönemlerden ilki geleneksel bütçe sisteminin uygulandığı 1924-1972 dönemi, bir sonraki dönem program bütçe sisteminin uygulandığ $1973-2005$ dönemi ve son dönem ise 5018 sayılı Kamu Mali Yönetimi ve Kontrol Kanunu'nun yürürlüğe girmesi ile uygulanmaya başlanan performans esaslı bütçeleme sistemidir. Bu nedenle tahmin hatasının ve eşitsizlik katsayılarının hesaplanması her bir dönem için ayrı ayrı yapılacaktır. Rasyonel beklentiler hipotezi içinse verilerin durağanlığın sağlanmasının şart olması nedeniyle böyle bir ayrım yapılmamıştır. Kullanılan yöntemlerin açıklanması sırasında olduğu gibi öncelikle tahmin hataları hesaplanarak bütçe tahmin doğruluğu incelenmeye başlanacaktır.

1924-1972 dönemi için hesaplanan tahmin hataları Ek 1'de sunulmuştur. Tabloya bakıldığında hem başlangıç ödenekleri hem de yılsonu ödenekleri için tahmin hatalarının 
ayrı olarak hesaplandığı görülmektedir. Tabloda yüksek ya da düşük tahmine bağlı olarak hesaplanan değerlerin negatif ya da pozitif değerler aldığı görülmektedir. Dönem ortalaması alınırken bu durum göz önünde bulundurularak hatalar mutlak değer olarak da ifade edilmiş ve dönem ortalamasında bu değerler kullanılmıştır.

Dönemin tamamına bakıldığında başlangıç ödenekleri açısından yapılan tahminler için \%12,5 hata oranı hesaplanmışken yılsonu ödenekleri tahmininde biraz daha başarılı olunduğu, dönemin tamamında \%10,2 oranında hata yapıldığı görülmektedir. Hatanın nedenine bakıldığında ise başlangıç ödeneklerinin genel olarak düşük tahmin edildiği yılsonu ödeneklerinin ise tam tersi olarak, sadece 1970 yllı haricinde, hep yüksek tahmin edildiği görülmektedir. Ek: 1'de yer alan tahmin hataları Grafik: 1'de gösterilmiştir. Grafikte de görebileceğimiz gibi başlangıç ödenekleri için hesaplanan tahmin hataları genel olarak pozitif olduğundan genel olarak düşük tahmin edildiği, yılsonu ödenek tahminlerinin ise tek bir yıl dışında hep negatif değerler alması nedeniyle de yüksek tahmin edildiği söylenebilir.

Grafik: 1

1924-1972 Dönemi Bütçe Tahmin Hataları

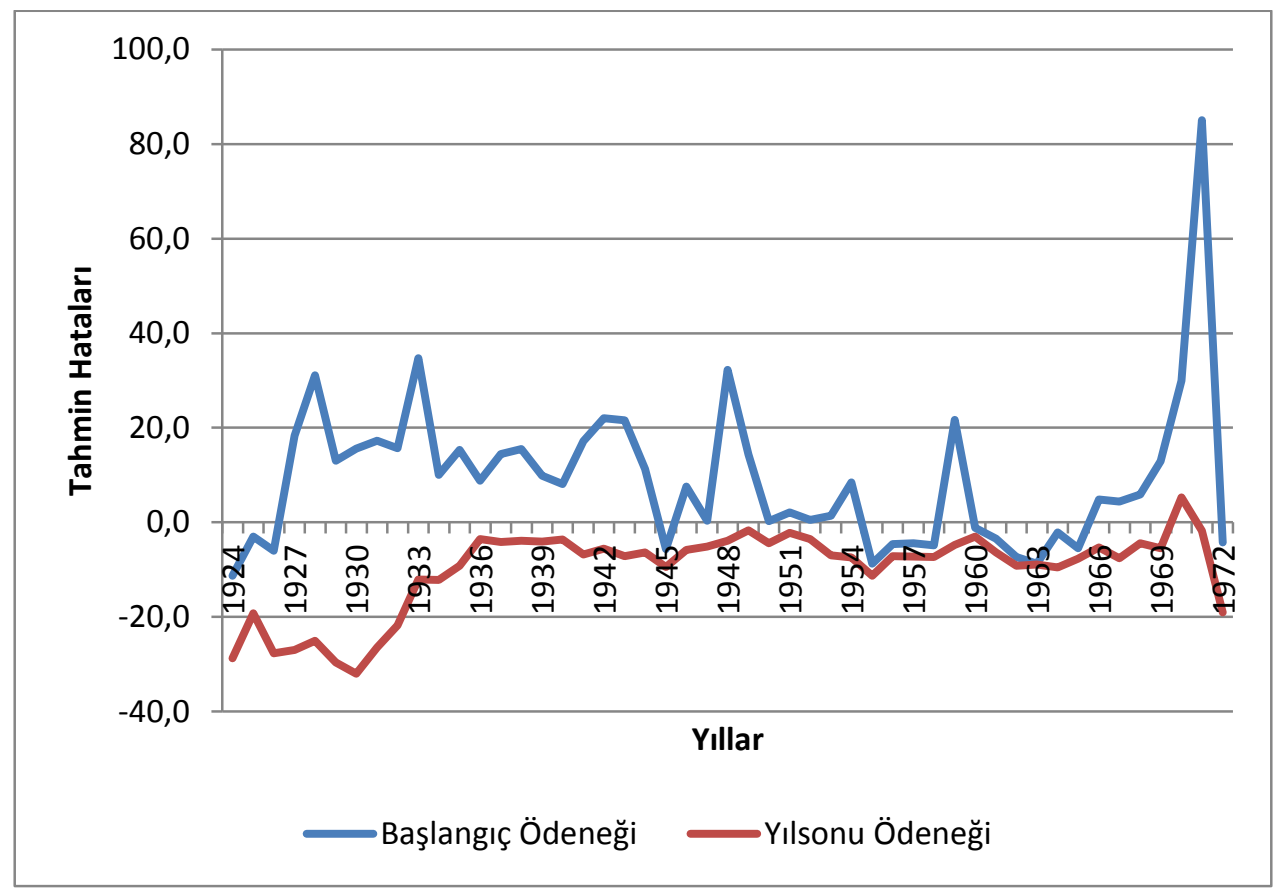

Başlangıç ödeneği açısından Maarif Vekâleti adı altında kurulan Bakanlığın ilk bütçesinde yaklaşık olarak \%11 oranında hata hesaplanmıştır. Daha sonraki dönemlere 
bakıldığında ise 1927-1935 dönemi, 1941-1944 dönemi ve 1969-1971 döneminde yüksek tahmin hatalarının yapıldığı görülmektedir. Hatta 1971 yılı için hesaplanan hata oranı \%85 gibi çok yüksek bir seviyededir. Bu yılda Bakanlık için başlangıç ödeneği 936,2 milyon TL olarak hesaplanmışken gerçekleşen harcama 6.248,0 milyon TL'dir (BÜMKO, 1992: 226).

Yılsonu ödeneklerinde yapılan tahmin hatalarına bakıldığında ise başlangıç ödeneklerine kıyasla daha başarılı olduklarını görmekteyiz. Dönemin tamamı için yapılan hataların ortalaması yaklaşık olarak \%10'dur. Tahmin hatalarına bakıldığında 1924-1935 döneminde yapılan hataların çok yüksek seviyelerde olduklarını görüyoruz. Bununla birlikte 1971 yılında başlangıç ödeneklerinde $\% 85$ gibi çok yüksek bir oranda yapılan hata yılsonu ödeneklerinde gerçeğe oldukça yaklaşmış bulunmaktadır. Fakat bir sonraki yılda bu durumun tam tersi gerçekleşmiş, başlangıç ödeneklerinde gerçeğe yakın bir tahmin yapılmışken yılsonu ödenekleri ile gerçekleşmelerden oldukça uzak bir tahmin yapılmıştır.

Grafik: 2

1973-2005 Dönemi Tahmin Hataları

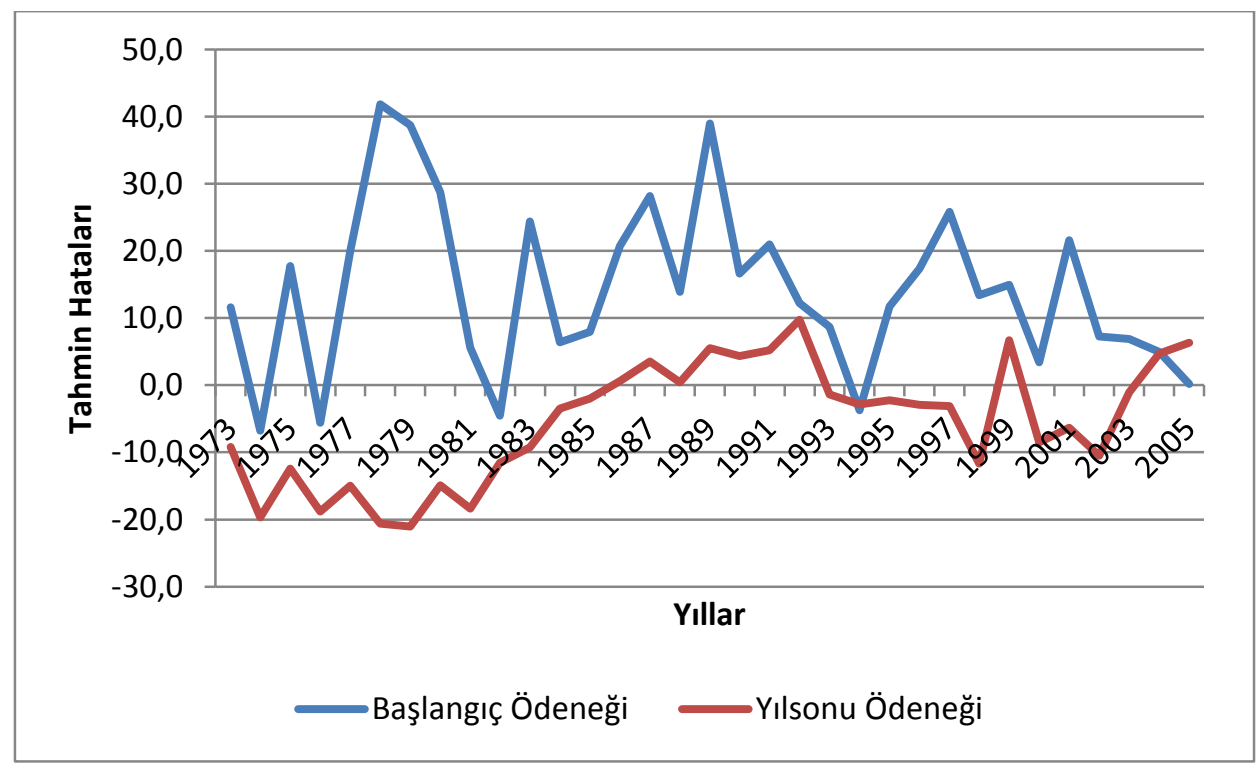

İncelenecek bir sonraki dönem olan, Program bütçe sisteminin uygulandığı, 19732005 döneminde yapılan tahmin hataları Ek: 2'de gösterilmiştir. Dönemin geneline baktığımızda başlangıç ödenekleri ile yılsonu ödenek tahminleri arasındaki fark daha fazla açılmışıı. Dönemin ortalama değerlerine bakacak olursak başlangıç ödenekleri tahmininde yapılan hata oranı $\% 15,5$, buna karşılık yılsonu ödenek tahminlerinde yapılan hata oranı $\% 8,3$ 'tür. Yapılan hataların genel eğilimlerine bakıldığında ise yine bir önceki dönemde olduğu gibi başlangıç ödeneklerinin genel olarak düşük tahmin edildiği, yılsonu 
ödeneklerinin ise bunun aksine genel olarak yüksek tahmin edildiği söylenebilir. Ek: 2'de yer alan tahmin hataları Grafik: 2 üzerinde gösterilmiştir.

Başlangıç ödeneklerinde yapılan tahmin hatalarına bakıldığında 1977-1980 dönemi, 1986-1992 dönemi ve 1995-1999 döneminde ve 1975, 1983 ve 2001 yıllarında diğer yıllara kıyasla daha fazla oranda hata yapıldığı görülmüştür. Yılsonu ödeneklerine baktığımızda ise 1974-1982 dönemi ile 1998 ve 2002 yıllarında daha fazla oranda hata yapıldığ1 görülmüştür.

İncelenecek son dönem olan performans esaslı bütçeleme sisteminin uygulandığ 1 2006-2012 dönemi için hesaplanan tahmin hataları Ek 3'de gösterilmiştir. Yedi yıllık bu kısa döneme bakıldığında başlangıç ödeneği tahmininde \%4,2; yılsonu ödenek tahminlerinde ise $\% 16,8$ oranında hata yapıldığı görülmüştür. Bir önceki yedi yıllık dönem olan 1999-2005 dönemi ortalamalarına bakıldığında başlangıç ödeneklerinde \%8,5; yılsonu ödeneklerinde ise \%6,2 oranında hata yapıldığı görülür. Yedi yıllık bu iki dönem karşılaştırıldığında başlangıç ödenekleri tahmininin iyileştiği yılsonu ödenek tahminlerinin ise kötüleştiği söylenebilir.

\section{Grafik: 3}

\section{5-2010 Dönemi Tahmin Hataları}

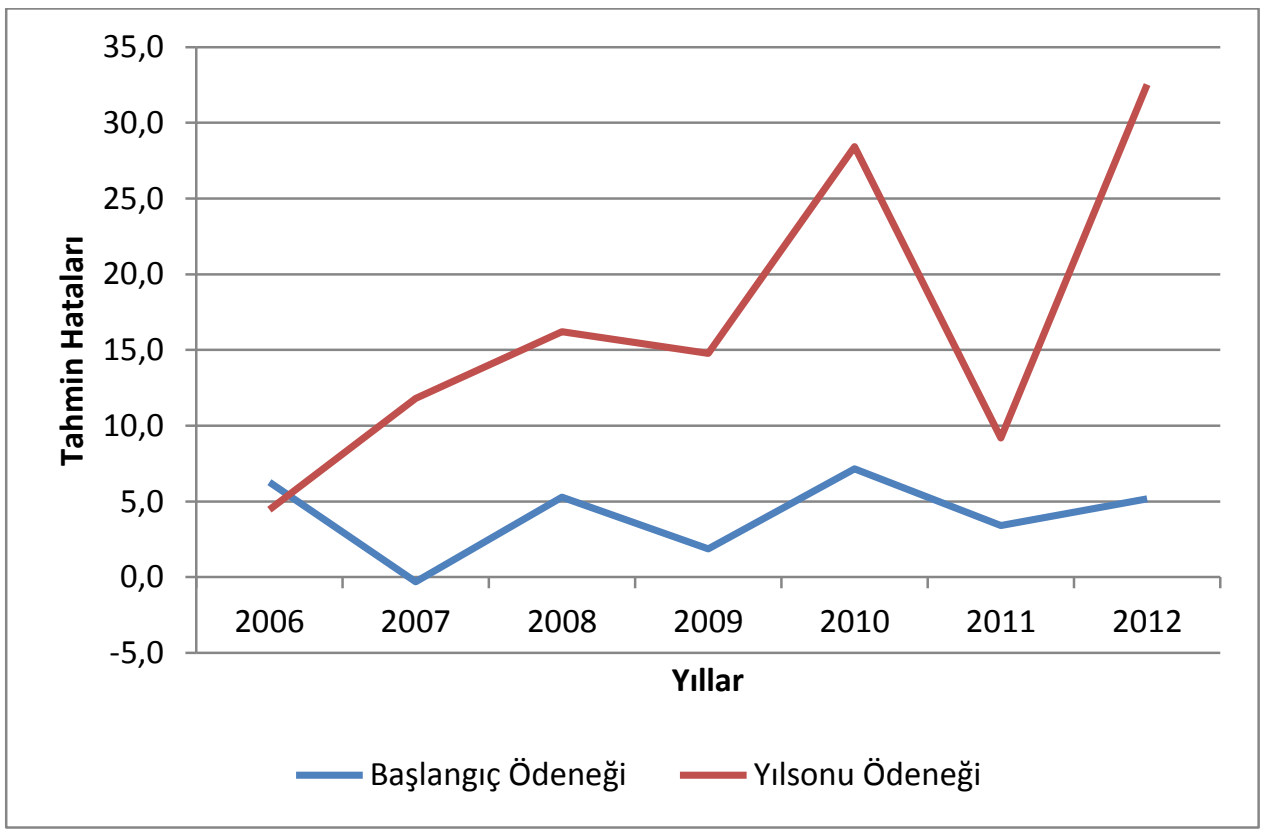


Başlangıç ve yılsonu ödenek tahminlerinde yapılan hatalara yıllar itibariyle bakıldığında 2007 yılı başlangıç ödeneği tahmini haricinde yapılan tahminlerin düşük olduğu görülmektedir. Başka bir ifade ile bu dönemde Bakanlığın harcamaları tahmin edilenden daha yüksek seviyelerde gerçekleşmiştir.

Tahmin başarısının değerlendirilmesinde kullanılan bir diğer yöntem Theil'ın eşitsizlik katsayılarıdır. Dönemler itibariyle hesaplanan eşitsizlik katsayıları Tablo: 1'de sunulmuştur.

\section{Tablo: 1}

\section{Dönemler İtibariyle Eşitsizlik Katsayıları}

\begin{tabular}{|c|c|c|c|c|c|c|}
\hline \multirow{2}{*}{ Dönemler } & \multicolumn{3}{|c|}{ Başlang1ç Ödeneği } & \multicolumn{3}{c|}{ Y1lsonu Ödeneği } \\
\cline { 2 - 7 } & U1 & U2 & U3 & U1 & U2 & U3 \\
\hline 1924-1972 Dönemi & 0,753324 & 3,246722 & 0,749157 & 0,085118 & 0,168724 & 0,066405 \\
\hline 1973-2005 Dönemi & 0,217454 & 0,447922 & 0,453866 & 0,07357 & 0,147192 & 0,136716 \\
\hline 2006-2012 Dönemi & 0,176168 & 0,363839 & 0,40589 & 0,473686 & 1,123048 & 0,685657 \\
\hline
\end{tabular}

Hesaplanan eşitsizlik katsayılarına bakıldığında son dönem hariç olmakla birlikte yılsonu ödenek tahminlerinin başlangıç ödeneklerine kıyasla daha başarılı olduğu görülmektedir. Son dönem sonuçları değerlendirilirken tahmin ve gerçekleşmelerin değişim olarak ifade edildiği ve bu nedenle kısa olan dönemin daha da kısaldığı göz önünde bulundurulmalıdır. İkinci eşitsizlik katsayısı hariç diğer katsayı değerlerinin 0 ile 1 arasında olması gerektiği göz önünde bulundurulacak olursa başlangıç ödenekleri tahminlerinin başarılı olmadığı söylenebilir. Bir üst değeri olmayan ikinci eşitsizlik katsayısının 19241972 dönemi için bu kadar yüksek olmasının nedeni olarak 1971 yılında başlangıç ödeneğinin çok düşük tahmin edilmiş olması düşünülmektedir. Hatırlanacağı gibi tahmin hatasının hesaplanması ile de yılsonu ödenek tahminlerinin başlangıç ödeneklerinden daha başarılı olduğu tespit edilmiştir.

Son olarak tahminlerin rasyonel beklentilere uygun olarak yapılıp yapılmadığı ikinci bölümde açılanan model kullanılarak test edilmiş ve Tablo: 2'de sunulan değerler elde edilmiştir. Modelde 1925-2012 döneminde başlangıç ödeneklerinin durağanlığının sağlanması için başlangıç ödeneklerinin logaritmasının alınarak birinci dereceden farkları alınmıştır. Yılsonu ödenekleri ve gerçekleşen harcamalara ise bir müdahalede bulunulması gerekmemiştir.

Tablo: 2

Rasyonel Beklentiler Hipotezi Test Sonuçları

\begin{tabular}{|c|c|c|c|c|c|}
\hline & $\alpha_{0}$ & $\alpha_{1}$ & $\alpha_{2}$ & $\mathrm{R}^{2}$ & $\sigma$ \\
\hline $\begin{array}{c}\text { Başlangıç } \\
\text { Ödeneği }\end{array}$ & 31230345 & $2.05 \mathrm{E}+08$ & $1.156295^{* * *}$ & 0.997677 & 0.841940 \\
\hline $\begin{array}{c}\text { Y1lsonu } \\
\text { Ödeneği }\end{array}$ & 33615134 & $0.237327 * * *$ & $0.934066^{* * *}$ & 0.998718 & 0.767265 \\
\hline
\end{tabular}

***\%1, **\%5 ve *\%10'da anlamlilık. 
Tablodaki değerlere bakacak olursak başlangıç ödeneği açısından gerçekleşen harcamaların gecikmelisi olarak ifade edilen katsayı haricinde, modeldeki katsayıların anlamsız oldukları görülür. Katsayıların anlamsız olması ve modelin genel açıklayıcılı̆̆ının \%99 gibi yüksek bir seviyede olması modelde çoklu doğrusallık probleminin işareti olabilir. Anlamlı olan katsayı ise kısıt testi sonucuna göre aranılan 0 değerinden farklıdır. Bunlara ilave olarak gerçekleşme ile tahmin arasındaki fark ile tahmin arasındaki ilişkiyi gösteren ve 0 değerini alması beklenen $\sigma, 0$ değerinden farklıdır.

Y1lsonu ödenekleri açısından yapılan tahminlerin rasyonelliğine bakıldığında ise tahmin ve gerçekleşmenin gecikmeli değerini gösteren katsayıların anlamlı olduğu, sabit terimin ise anlamsız olduğu görülür. Anlamlı olan katsayılar ise kısıt testlerine göre aranılan 1 ve 0 değerlerinden farklıdır. Yılsonu ödenekleri ile kurulan modelin genel açıklayıcılığına bakıldığında ise modelin \%99 oranında bu değişkenlerle açıklandığı görülmektedir. İlaveten başlangıç ödeneklerinde olduğu gibi tahmin hatası ile tahmin arasındaki korelasyonu gösteren katsayı 0 değerinden farklıdır.

$\mathrm{Bu}$ sonuçlara bakıldığında ne başlangıç ödeneği tahminlerinin ne de yılsonu ödeneği tahminlerinin rasyonel beklentiler için gerekli olan koşulları sağladığı söylenebilir.

\section{Sonuç}

Eğitime yapılan harcamalarının ülkenin kalkınma seviyesi üzerinde önemli bir yeri vardır ve bunun yanı sıra, giriş bölümünde de ifade edildiği gibi, ülke kaynaklarının hatırı sayılır bir kısmı Milli Eğitim Bakanlığı'na ayrılmaktadır. Hem kaynakların etkin bir şekilde kullanılması hem de kalkınmadaki önemli rolü nedeniyle eğitime yapılan harcamaların tahmin başarısının incelenmesi gerektiği düşünülmüştür. Değerlendirmede kullanılan veriler kaynakların etkili bir şekilde kullanılması amaciyla uygulanan farklı bütçeleme sistemleri göz önünde bulundurularak ayrı ayrı ele alınmıştır. Bütçeleme sistemlerinden beklenilenlerin elde edilip edilememesi açısından da bütçe tahminlerinin doğru olarak yapılması önemlidir. Çalışma sonucunda 1924-2012 döneminde ödenek tahminlerinin başarılı bir şekilde yapılamadığg görülmüştür.

Geleneksel bütçe sisteminin uygulandığ 1924-1972 döneminde başlangıç ödeneklerinde yapılan hata \%12,5 iken yılsonu ödeneklerinde \%10,2 oranında hata yapılmıştır. Bu dönemde yapılan ödenek tahminlerine baktığımızda başlangıç ödenekleri ve yılsonu ödenek tahminlerinde yaklaşık olarak aynı oranda hata yapıldığı görülmektedir. Tahminler arasındaki farkın, başlangıç ödeneklerinin genel olarak düşük tahmin edilmesi yılsonu ödeneklerinin ise yüksek tahmin edilmesi olduğu söylenebilir. Theil'ın eşitsizlik katsayılarına bakıldığında 0 ile 1 değerleri arasında bir değer alması gereken $U_{1}$ ve $U_{2}$ katsayılarının yüksek bir değer alması nedeniyle başlangıç ödenekleri tahmininde ciddi oranda hata yapıldığı fakat yılsonu ödenek tahminlerinde daha başarılı olunduğu söylenebilir. 
1973 y1lı itibariyle uygulanmaya başlanan ve 2005 yılına kadar uygulanan program bütçe sisteminde ise başlangıç ödenekleri tahmininde yapılan hatanın geleneksel bütçe sisteminde yapılan hataya kıyasla nispeten daha büyük, yılsonu ödenek tahminleri açısından ise daha küçük olduğu görülmektedir. Eşitsizlik katsayıları açısından ise başlangıç ödenekleri açısından bir önceki döneme göre daha başarılı tahminlerin yapıldığı görülmektedir. Yılsonu ödenek tahminleri için hesaplanan eşitsizlik katsayı değerleri bir önceki dönem için hesaplanan değerlere yakındır. Bununla birlikte bu dönemde başlangıç ödenekleri tahmininde iyileşmenin olduğu söylenebilir.

Dönem uzunluğu açısından önceki iki dönemle karşılaştırılamayacak olmakla birlikte stratejik plana dayalı performans esaslı bütçeleme sisteminde, diğer dönemlerin aksine, bakanlık ödenek tahminlerinin başlangıç ödeneklerinde yılsonu ödeneklerine kıyasla daha başarılı olduğu görülmektedir. 2006-2012 döneminde başlangıç ödenekleri tahmininde yapılan hata \%4,2 iken yılsonu ödeneklerinde yapılan hata \%16,8'dir. Geleneksel ve program bütçe sistemlerinde yılsonu ödenek tahminleri yüksek yapılmışken ilgili dönemde yılsonu ödeneklerinin de düşük tahmin edildiği görülmektedir. Dönemin çok kısa olması nedeniyle eşitsizlik katsayılarının sağlıklı olarak yorumlanamayacağı bilinmekle birlikte katsayı sonuçlarına göre de başlangıç ödeneklerinin yılsonu ödeneklerine kıyasla daha başarılı olduğu söylenebilir.

Tahmin hataları ve eşitsizlik katsayılarının incelenmesinde sonra son olarak yapılan tahminlerin rasyonel beklentiler hipotezine uygun olarak yapılıp yapılmadığı test edilmiştir. Özetle bütçe tahminlerinin bir önceki yıl gerçekleşmelerinden bağımsız yapılması olarak ifade edilebilecek rasyonel beklentiler hipotezinin test edilmesi sonucunda bütçe tahminlerinin rasyonel beklentilere uygun olarak yapılmadığı görülmüştür. Sonuç olarak çalışma sonucunda Milli Eğitim Bakanlığg ödenek tahminlerinin doğru olarak yapılmadığ görülmüştür.

\section{Kaynakça}

Allan. (1965), “Fiscal Marksmanship, 1951-63”, Oxford Economic Papers, 317-327.

Asher. (1978), “Accuracy of Budgetary Forecast of Central Government, 1967-68 to1975-76”, Economic and Political Weekly, 423-432.

Auld, D.A. (1970), "Fiscal Marksmanship in Canada”, The Canadian Journal of Economics, 507511.

Bağdigen, M. (2005), “An Empirical Analysis of Accurate Budget Forecasting in Turkey”, Doğuş Üniversitesi Dergisi, 6(2), 190-201

Bağdigen, M. (2002), "How Accurate is Revenue Forecasting in Turkey? An Empirical Analysis", Yapı Kredi Economic Review, Vol. 13, No. 2, 29-37.

Berger, N. \& P. Fisher (2013), “A well-educated workforce is key to state prosperity”, Economic Analysis and Research Network Report, 22 August, Available at: <http://www.epi.org/ files/2013/A\%20welleducated $\% 20$ workforce $\% 20$ is $\% 20$ key $\% 20$ to $\% 20$ state $\% 20$ prosperity.pdf $>, 23.01 .2014$. 
Bhattacharya, B.B. \& A. Kumari (1988), "Budget Forecast of Central Government Revenue and Expenditure: A Test of Rational Expectation”, Economic and Political Weekly, Vol.23, No.26, 1323-1327.

BÜMKO (1992), Bütçe Gider ve Gelir Gerçekleşmeleri (1924-1991), Ankara: T.C. Maliye ve Gümrük Bakanlığı Bütçe ve Mali Kontrol Genel Müdürlüğü.

Chakraborty, L.S. \& D. Sinha (2008), "Budgetary Forecasting in India: Partitioning Errors and Testing for Rational Expectations", Munich Personal RePEc Archive (MPRA), Working Paper No.7538.

Davis, J. (1980), "Fiscal Marksmanship in the United Kingdom, 1951-78”, The Manchester School, 187-202.

Edizdoğan, N. \& Ö. Çetinkaya (2010), Kamu Bütçesi. Bursa: Ekin Basım Yayın Dağıtım.

Froyen, R.T. (2008), Macroeconomics Theories and Policies, (Ninth Edition), Pearson International Edition.

Günlük Şenesen, G. (2000), "Bütçe Başlangıç Ödeneklerinin Başarımının Değerlendirilmesinde Nicel Yaklaşımlar", 15. Türkiye Maliye Sempozyumu, Antalya, 345-376.

Gürsoy, B. (1980), Kamusal Maliye, Ankara: Ankara Üniversitesi Siyasal Bilgiler Fakültesi Yayınları No:436.

Lovell, M.C. (1986), "Tests of the Rational Expectations Hypothesis", The American Economic Review, Vol. 76, No. 1, 110-124.

Morrison, R. (1986), "Fiscal Marksmanshipin the United States: 1950-83", Manchester School of Economic and Social Studies, 322-333.

Muhasebat Genel Müdürlüğü (2014), <https://portal.muhasebat.gov.tr/mgmportal/faces/khb_yeni?_afrLoop=14752865852161 76\&_afrWindowMode $=0 \&$ _adf.ctrl-state $=$ d3g3bnpve_73>, 20.02.2014 .

Muth, J.F. (1961), "Rational Expectations and the Theory of Price Movements", Econometrica, Vol.29, No.3, 315-335.

Özcan, S. (2012), “Genel Bütçe Gelir ve Harcama Tahminlerinin Analizi: Türkiye Üzerine Ekonometrik Bir İnceleme”, Basılmamış Yüksek Lisans Tezi, Hacettepe Üniversitesi, Sosyal Bilimler Enstitüsü, Maliye Anabilim Dalı, Ankara.

Rodgers, R. \& P. Joyce (1996), "The Effect of Underforecasting on the Accuracy of Revenue Forecasts by State Governments", Public Administration Review, Vol.56, No. 1, 48-56.

Theil, H. (1965), Economic Forecasts and Policy, Amsterdam: North-Holland Publishing Company. Theil, H. (1971), Applied Economic Forecasting, Amsterdam: North-Holland Publishing Company. Y1lmaz, H.H. (2003), Konsolide Bütçe Gelir ve Gider Tahminlerinin Gerçekleşmelere Göre Güvenilirlik Düzeyi [Bildiri], METU ERC.

Zakaria, M. \& S. Ali (2010), "Fiscal Marksmanship in Pakistan", The Lahore Journal of Economics, Vo.15, No.2, 113-133. 
Ek: 1

1924-1972 Dönemi M.E.B. Ödenek Tahmin Hataları

\begin{tabular}{|c|c|c|c|c|c|c|c|c|c|}
\hline \multirow[b]{2}{*}{ Yillar } & \multicolumn{2}{|c|}{ Başlangıç Ödeneği } & \multicolumn{2}{|c|}{ Y1lsonu Ödeneği } & \multirow[b]{2}{*}{ Yillar } & \multicolumn{2}{|c|}{ Başlangıç Ödeneği } & \multicolumn{2}{|c|}{ Y1lsonu Ödeneği } \\
\hline & $\begin{array}{c}\text { Tahmin } \\
\text { Hatası }(\mathrm{TH})\end{array}$ & lTHl & $\begin{array}{c}\text { Tahmin } \\
\text { Hatası }(\mathrm{TH})\end{array}$ & lTHl & & $\begin{array}{c}\text { Tahmin } \\
\text { Hatas1 }(\mathrm{TH})\end{array}$ & ITHl & $\begin{array}{c}\text { Tahmin } \\
\text { Hatası }(\mathrm{TH})\end{array}$ & ITHl \\
\hline 1924 & $-11,3$ & 11,3 & $-28,7$ & 28,7 & 1949 & 14,3 & 14,3 & $-1,7$ & 1,7 \\
\hline 1925 & $-3,0$ & 3,0 & $-19,2$ & 19,2 & 1950 & 0,2 & 0,2 & $-4,4$ & 4,4 \\
\hline 1926 & $-6,0$ & 6,0 & $-27,7$ & 27,7 & 1951 & 2,1 & 2,1 & $-2,2$ & 2,2 \\
\hline 1927 & 18,3 & 18,3 & $-27,0$ & 27,0 & 1952 & 0,5 & 0,5 & $-3,5$ & 3,5 \\
\hline 1928 & 31,1 & 31,1 & $-25,1$ & 25,1 & 1953 & 1,4 & 1,4 & $-7,0$ & 7,0 \\
\hline 1929 & 13,1 & 13,1 & $-29,7$ & 29,7 & 1954 & 8,5 & 8,5 & $-7,4$ & 7,4 \\
\hline 1930 & 15,6 & 15,6 & $-32,0$ & 32,0 & 1955 & $-8,7$ & 8,7 & $-11,3$ & 11,3 \\
\hline 1931 & 17,2 & 17,2 & $-26,4$ & 26,4 & 1956 & $-4,6$ & 4,6 & $-7,1$ & 7,1 \\
\hline 1932 & 15,7 & 15,7 & $-21,8$ & 21,8 & 1957 & $-4,4$ & 4,4 & $-7,3$ & 7,3 \\
\hline 1933 & 34,7 & 34,7 & $-12,1$ & 12,1 & 1958 & $-4,9$ & 4,9 & $-7,3$ & 7,3 \\
\hline 1934 & 10,0 & 10,0 & $-12,1$ & 12,1 & 1959 & 21,6 & 21,6 & $-4,7$ & 4,7 \\
\hline 1935 & 15,3 & 15,3 & $-9,1$ & 9,1 & 1960 & $-1,2$ & 1,2 & $-3,0$ & 3,0 \\
\hline 1936 & 8,8 & 8,8 & $-3,5$ & 3,5 & 1961 & $-3,4$ & 3,4 & $-6,3$ & 6,3 \\
\hline 1937 & 14,4 & 14,4 & $-4,1$ & 4,1 & 1962 & $-7,4$ & 7,4 & $-9,2$ & 9,2 \\
\hline 1938 & 15,5 & 15,5 & $-3,9$ & 3,9 & 1963 & $-8,7$ & 8,7 & $-8,9$ & 8,9 \\
\hline 1939 & 9,8 & 9,8 & $-4,1$ & 4,1 & 1964 & $-2,1$ & 2,1 & $-9,5$ & 9,5 \\
\hline 1940 & 8,1 & 8,1 & $-3,6$ & 3,6 & 1965 & $-5,5$ & 5,5 & $-7,7$ & 7,7 \\
\hline 1941 & 17,2 & 17,2 & $-6,8$ & 6,8 & 1966 & 4,9 & 4,9 & $\begin{array}{l}-5,3 \\
\end{array}$ & 5,3 \\
\hline 1942 & 22,0 & 22,0 & $-5,6$ & 5,6 & 1967 & 4,4 & 4,4 & $-7,6$ & 7,6 \\
\hline 1943 & 21,6 & 21,6 & $-7,1$ & 7,1 & 1968 & 5,9 & 5,9 & $-4,5$ & 4,5 \\
\hline 1944 & 11,3 & 11,3 & $-6,3$ & 6,3 & 1969 & 12,9 & 12,9 & $-5,5$ & 5,5 \\
\hline 1945 & $-5,7$ & 5,7 & $-9,4$ & 9,4 & 1970 & 30,0 & 30,0 & 5,2 & 5,2 \\
\hline 1946 & 7,5 & 7,5 & $-5,8$ & 5,8 & 1971 & 85,0 & 85,0 & $-1,8$ & 1,8 \\
\hline 1947 & 0,3 & 0,3 & $-5,1$ & 5,1 & 1972 & $-4,2$ & 4,2 & $-19,1$ & 19,1 \\
\hline 1948 & 32,2 & 32,2 & $-3,9$ & 3,9 & Ortalama & 9,2 & 12,5 & $-9,9$ & 10,2 \\
\hline
\end{tabular}

Kaynak: BÜMKO (1992)'den alınan verilerden derlenmiştir. 
Ek: 2

1973-2005 Dönemi M.E.B. Ödenek Tahmin Hataları

\begin{tabular}{|c|c|c|c|c|c|c|c|c|c|}
\hline \multirow[b]{2}{*}{ Yillar } & \multicolumn{2}{|c|}{ Başlangıç Ödeneği } & \multicolumn{2}{|c|}{ Y1lsonu Ödeneği } & \multirow[b]{2}{*}{ Yillar } & \multicolumn{2}{|c|}{ Başlangıç Ödeneği } & \multicolumn{2}{|c|}{ Y1lsonu Ödeneği } \\
\hline & $\begin{array}{c}\text { Tahmin } \\
\text { Hatası (TH) }\end{array}$ & ITH1 & $\begin{array}{c}\text { Tahmin } \\
\text { Hatası (TH) }\end{array}$ & 1THI & & $\begin{array}{c}\text { Tahmin } \\
\text { Hatası (TH) }\end{array}$ & 1TH1 & $\begin{array}{c}\text { Tahmin } \\
\text { Hatası (TH) }\end{array}$ & 1TH1 \\
\hline 1973 & 11,6 & 11,6 & $-9,2$ & 9,2 & 1990 & 16,6 & 16,6 & 4,4 & 4,4 \\
\hline 1974 & $-6,8$ & 6,8 & $-19,7$ & 19,7 & 1991 & 21,0 & 21,0 & 5,2 & 5,2 \\
\hline 1975 & 17,8 & 17,8 & $-12,4$ & 12,4 & 1992 & 12,2 & 12,2 & 9,7 & 9,7 \\
\hline 1976 & $-5,6$ & 5,6 & $-18,8$ & 18,8 & 1993 & 8,7 & 8,7 & $-1,4$ & 1,4 \\
\hline 1977 & 20,0 & 20,0 & $-15,0$ & 15,0 & 1994 & $-3,8$ & 3,8 & $-2,9$ & 2,9 \\
\hline 1978 & 41,9 & 41,9 & $-20,6$ & 20,6 & 1995 & 11,8 & 11,8 & $-2,2$ & 2,2 \\
\hline 1979 & 38,7 & 38,7 & $-21,0$ & 21,0 & 1996 & 17,4 & 17,4 & $-2,9$ & 2,9 \\
\hline 1980 & 28,7 & 28,7 & $-14,9$ & 14,9 & 1997 & 25,8 & 25,8 & $-3,1$ & 3,1 \\
\hline 1981 & 5,6 & 5,6 & $-18,4$ & 18,4 & 1998 & 13,4 & 13,4 & $-11,7$ & 11,7 \\
\hline 1982 & $-4,5$ & 4,5 & $-11,6$ & 11,6 & 1999 & 15,0 & 15,0 & 6,7 & 6,7 \\
\hline 1983 & 24,4 & 24,4 & $-9,2$ & 9,2 & 2000 & 3,4 & 3,4 & $-8,5$ & 8,5 \\
\hline 1984 & 6,4 & 6,4 & $-3,5$ & 3,5 & 2001 & 21,6 & 21,6 & $-6,3$ & 6,3 \\
\hline 1985 & 8,0 & 8,0 & $-2,0$ & 2,0 & 2002 & 7,2 & 7,2 & $-10,5$ & 10,5 \\
\hline 1986 & 20,7 & 20,7 & 0,6 & 0,6 & 2003 & 6,9 & 6,9 & $-1,1$ & 1,1 \\
\hline 1987 & 28,2 & 28,2 & 3,5 & 3,5 & 2004 & 5,0 & 5,0 & 4,7 & 4,7 \\
\hline 1988 & 13,9 & 13,9 & 0,4 & 0,4 & 2005 & 0,2 & 0,2 & 6,3 & 6,3 \\
\hline 1989 & 39,0 & 39,0 & 5,5 & 5,5 & Ortalama & 14,3 & 15,5 & $-5,4$ & 8,3 \\
\hline
\end{tabular}

Kaynak: BÜMKO (1992) ve Muhasebat Genel Müdürlüğ̈̈'nden alınan verilerden derlenmiştir.

Ek: 3

2006-2010 Dönemim M.E.B. Ödenek Tahmin Hataları

\begin{tabular}{|c|c|c|c|c|}
\hline \multirow{2}{*}{ Yıllar } & \multicolumn{2}{|c|}{ Başlangıç Ödeneği } & \multicolumn{2}{c|}{ Yllsonu Ödeneği } \\
\cline { 2 - 5 } & Tahmin Hatası (TH) & $1 T H 1$ & Tahmin Hatası (TH) & lTHl \\
\hline 2006 & 6,3 & 6,3 & 4,4 & 11,4 \\
\hline 2007 & $-0,3$ & 0,3 & 1,8 & 1,8 \\
\hline 2008 & 5,3 & 5,3 & 16,2 & 16,2 \\
\hline 2009 & 1,9 & 1,9 & 14,8 & 28,4 \\
\hline 2010 & 7,2 & 7,2 & 28,4 & 9,2 \\
\hline 2011 & 3,4 & 3,4 & 9,2 & 32,5 \\
\hline 2012 & 5,2 & 5,2 & 32,5 & $\mathbf{1 6 , 8}$ \\
\hline Ortalama & $\mathbf{4 , 1}$ & $\mathbf{4 , 2}$ & $\mathbf{1 6 , 8}$ & \\
\hline
\end{tabular}

Kaynak: Muhasebat Genel Müdürlügü'nden alınan verilerden derlenmiştir. 
Sibel ÖZCAN \& Mustafa Umur TOSUN 